\title{
13
}

\section{Administration, management and IT in education}

\author{
I.D. Selwood and H. Drenoyianni \\ School of Education, The University of Birmingham \\ Edgbaston, Birmingham, B15 2TT, UK \\ Phone: (44)-121-4144851 \\ Fax: (44)-121-4144865 \\ e-mail: I.D.Selwood@Bham.AC.UK
}

\begin{abstract}
This paper examines how computerised Management Information Systems (MISs) can support the information and decisional needs of educational managers. Furthermore, the capabilities of such information systems will de described and discussed together with the benefits of using Information Technology (IT) in managing educational organisations. Section three of the paper describes a small scale piece of research that examined senior educational managers' perceptions and usage of IT in Educational Management (ITEM), and suggests some reasons for the lack of usage of IT to support management decision making.
\end{abstract}

\section{Keywords}

Educational management, information technology, administration, management

\section{INTRODUCTION}

Visscher (1995) in his paper entitled 'Computer Assisted School Administration and Management: Where are we and where should we go?' outlined four stages of the development of Computer Assisted School Administration (CASA). Whilst it is difficult to disagree with his first two stages, 'initiation' and 'expansion', he claims: "the third stage 'integration' can be 'characterised by 'integrated modules' and 'the production of management information"' (Visscher, 1995); and that the fourth stage, 'stabilisation', can be characterised by computer assistance reaching its full potential and the focus shifting to systems maintenance and refinement. These final two stages are somewhat open to debate. It is possible that systems, even though they may comprise 'integrated modules', may not be flexible enough to provide information for management decisions (Mitchell and Wild, 1993). Other considerations such as: lack of appropriate training for senior educational managers; and constant revision of systems due to technological change, may also inhibit progress. In the UK it would appear that the third stage of the evolution of CASA is basically that i.e. the use of computers to aid school 
administration, and that the fourth stage is the development of the use of ITEM (Information Technology in Educational Management) i.e. the use of computerised MISs (Management Information Systems) to support Educational Managers.

It is perhaps, sensible for the purpose of this paper to distinguish between administration and management. Administration can be thought of as the tasks associated with the day to day running of an organisation that ensure that the organisation performs smoothly and efficiently to achieve its pre-determined goals. Management, however, is concerned with analysing information, making decisions, defining strategies, tactics, and goals for the organisation and ensuring that an organisation works towards these goals in an efficient and effective manner (Fidler and Bowles, 1989). Goals and strategies will need periodic re-appraisal to ensure that they remain appropriate.

\section{COMPUTER-BASED MANAGEMENT INFORMATION SYSTEMS}

In the UK, the Education Reform Act (ERA) (House of Commons, 1988) required that headteachers and governing bodies in every school should embrace a role similar to that of managers in commercial companies. According to the DES, they (governing bodies) should 'formulate a management plan for the school' and 'secure its implementation with the collective support of the school's staff' (DES, 1988). They should be concerned with managing the budget, the curriculum, human resources, premises, property and learning resources. Particularly, they should make decisions and be responsible for the impact and implications of their decisions on the running of the school. As experience in commercial and industrial organisations has shown, 'effective decisions must be based on a steady flow of quality, up-to-date information' (Thierauf, 1987). Educational managers need also to consider the value and the nature of information needed for decision making and strategic planning activities, and decide upon "the form and extent of their management information system" (Strain, 1990).

Computer-based management information systems have been used for some time in commerce for storing, processing and transforming data to information that is valuable for supporting managers in their duties. Moreover, the Coopers and Lybrand report (1988) for local management of schools, a key feature of the ERA, had identified the need for computerised management information systems. It is therefore apparent that educational managers are expected to take advantage of the computers' potential, to store and process rapidly and accurately vast amounts of data, by using MISs to augment their managerial and administrative responsibilities.

The question raised here concerns the nature of a computerised MIS and how educational managers can benefit from using them. Definitions of MISs are multiple and varied. Several authors (Hicks, 1993; Thierauf, 1987) agree that a number of information systems, such as Decision Support Systems or Executive Information Systems, fall under the umbrella of Management Information Systems, while others (Bank and Williams, 1987; Carter and Burger, 1994) consider them as significantly different systems designed for a specific purpose. A lengthy discussion concerning the technicalities of such distinctions is inappropriate here. A good useful working definition coming from the former category of writers, which concentrates on the general use of MISs, is probably appropriate. Accordingly a computer-based MIS is "an integrated user-machine system for providing information to support operations, management, and decision-making functions in an organisation" (Davis and Olson, 1985)

The above statement infers that there is an interactive relationship between the user and the computer, a dialogue, in which both are engaged in "different but complementary roles" (Levacic, 1995). Further it stresses the need to support "management and decision making functions." Computers can help educational managers to access large amounts of data in a timely and accurate manner but it is the managers who actually find relations, 
interpret and give meaning to the data. However, having stated this, it is clear that computers can connect and combine data but only if they are instructed to do so - the design of the MIS is therefore crucial to the sort of query it can answer, and the type of decisions it can support. This capability of computers to associate data, when they are instructed to do so, can be seen through a description of the components used in the database approach to information processing on which the structures of most MISs are based. According to Hicks (1993), one component of the database environment is the user. The users - educational managers and staff in a school, for example - communicate with the database through a number of application programmes by inputting, differentiating, cutting out and manipulating data for pupils, teachers, premises and generally everything about a school. The application programmes used, can be general, such as word-processors or spreadsheets, or specific, i.e., concerned with budgeting, planning school development, managing the curriculum, managing staff development, school appraisal, pupil records, premises, learning resources, accounts, payroll or attendance.

The database approach as applied in most MISs' structures has the major advantage of arming managers who use such systems with a major 'weapon' against their demanding managerial responsibilities: information based on a thorough, broad and coherent collection of data. All the data contained in the specific application programmes of the system for administrative purposes can be accessed and managed in an integrated way. This is particularly important for educational managers. For example, it should enable educational managers to bring together data about pupils, parents, teachers, attendance and timetable to investigate truancy by analysing data, seeking trends and patterns, hypothesising on possible reasons and forming appropriate policies. This policies, once implemented can then be analysed in a similar manner. This sort of analysis can support educational managers in understanding and gaining insights into particular educational setting's structures and operations. "Decision-making in educational institutions involves a complex process that requires the structuring of a broad range of alternatives and the analysis of numerous policy variables." (Cameron Fisher et al., 1990)

Since MISs, as a consequence of their structures, can be responsive to the above requirements, their use can support educational managers in making decision, more easily and efficiently. To be more specific, people who are most responsible for managing a particular school, like managers in commercial organisations (Hicks, 1993), make decisions of different types and at different levels, by following certain stages in order to find solutions.

The management process is primarily concerned with decision making. Whenever for example, headteachers and governing bodies in a school form a vision of where the school is going, establish aims and objectives, prioritise them and develop a plan for the accomplishment of these objectives, they are involved in strategic decision making. Whenever, they are making decisions concerned with the implementation of the school's development plan (e.g. appoint or dismiss teaching or other staff), their decisions may be considered as tactical. Finally, whenever they have to carry out clear and specific tasks (e.g. ordering supplies) they are making operational decisions.

A well designed and implemented MIS should be capable of supporting all types of decision making, no matter the level. Consequently MISs should assist educational managers in planning, organising, controlling, reviewing, monitoring and evaluating procedures. In particular, they should be able to supply managers with precise and consistent information for the identification of problems, the analysis of the problem to its smaller and controllable parts, the identification of alternative solutions to it, the examination and evaluation of each solution's feasibility and the prediction of their implications. In other words, MISs should help educational managers to give answers to questions like (Telem, 1990): (1) 'What has happened?' (e.g., In which areas of the curriculum do students fail to achieve high grades?) (2) 'Why did it happen?' (e.g. What are the possible causes of certain groups of students' under-achievement?) (3) 'What would happen if....?' (e.g. What would happen if we changed the methods of assessing 
pupils? What would happen to the budget if we changed the card index library system to a computerised system?). It should be possible with an MIS to produce reports: required by statute, about the school's general operation; for discovering and analysing particular problems; and producing highly specific reports responsive to varied needs and requests. MISs should also improve the presentation of information and data. All of these reports and presentations could be supported by graphics. It is self evident that MISs should also be capable of performing rapid statistical and mathematical analysis, this is not only particularly essential in financial and budgetary planning, but also in many of the previously mentioned applications. With the addition of local area networks and electronic mail facilities MISs should also improve communication amongst not only users in the school, but also between the school and the LEA, public examination boards, educational suppliers, and other schools, etc.

There are significant benefits in using MISs in educational management, but educational managers can only profit from them if they are aware of, and take advantage of the capabilities outlined above.

\section{MANAGEMENT INFORMATION SYSTEMS - USE IN SCHOOLS?}

\subsection{Background}

During 1995 a series of two day residential conferences were run for senior educational managers, headteachers and deputy headteachers, entitled 'Making SIMS' 1 Work for You'. The objectives of the conference were wide, but included the objective of raising awareness of the management uses of IT. An independent, follow-up evaluation of the conferences was carried out by the authors of this paper, in early 1996. As a part of this evaluation survey the perceptions of senior educational managers regarding the use of ITEM, their previous training in educational management and their actual uses of ITEM, were investigated. The following sections report on this part of the survey.

\subsection{Methodology and Objectives}

A postal survey of the conference delegates was undertaken in January 1996. The prime purpose of the research was to try to evaluate the lasting effectiveness of the series of conferences, which took place between February and June 1995. Whilst the particular results concerning the conferences are interesting they are beyond the general scope of this paper. The second part of the questionnaire concerned perceptions and uses of IT in educational management in general (and SIMS in particular) and had the following objectives:

- To ascertain whether the respondents felt that the conference had helped them to use SIMS for management purposes;

- To find out if the respondents had ever attended a management training course, and details of these courses;

- To ascertain if the respondents felt that their current SIMS systems could be used as a management tool;

- To investigate what modules in SIMS were being used for management purposes.

\footnotetext{
${ }^{1}$ SIMS (Schools Information Management System) - The market leader in proprietary software for educational administration and management in the UK (Selwood, 1995).
} 


\subsection{Questionnaire Design}

The part of the questionnaire with which we are concerned used a variety of question types. Some questions were open ended, others closed, and others expected a ranking. To ensure that all respondents were aware of the distinction being sought between 'educational administration' and 'educational management' their attention was drawn to an appendix to the questionnaire that contained definitions of the two terms.

\subsection{Results}

The response rate for a postal questionnaire was quite good, 70 percent. This consisted of 29 (74\% of the possible respondents) primary schools, $1(50 \%)$ middle, and $8(61 \%)$ secondary. The ratio of 29:1:8 also corresponds well to the proportions of the types of school in the geographical area covered by the survey. The numbers are low, but we do feel they are a good representative sample. Moreover, all had chosen to attend a conference and all had been using SIMS for at least 2 years, some much longer.

In response to the question "Do you feel the conference helped you to use SIMS for management purposes?" the majority responded positively, but, 16 percent felt the conference had not helped. However, it should be noted, in relation to a later question concerning whether the respondents felt their current SIMS system "could be used as a management tool", these 16 percent also expressed a negative view.

When asked about their attendance on management training courses, all the headteachers (26) responded that they had attended management training courses. The types of course attended varied greatly, from M.Ed courses (2), through diploma courses (4), to a half day course (1). Several respondents did comment that their courses had contained no IT component. Of the other respondents (12), who were not headteachers, only one had attended a management course.

The responses to a series of questions concerning the use of SIMS as a management tool were in general positive. However, a significant percentage $(18 \%)$ felt their current SIMS system could not be used as a management tool. Of these, 57 percent said that this was due to SIMS not being suitable, and 86 percent said that there was lack of management understanding of how to use SIMS as a management tool. An additional three respondents also noted lack of management's understanding of the use of SIMS as a management tool as a problem, giving 24 percent of total respondents noting this.

The respondents were asked if their school used SIMS for management purposes. Almost 60 percent (57\% of primary, 62\% secondary, and the middle school did not) claimed their schools did use SIMS for management purposes - 42 percent claimed their school did not use SIMS for management purposes or did not respond to the question. Of the respondents who claimed their schools did use SIMS for management purposes all cited the financial management module (LRM) - used for budget planning, with 32 percent giving this is as the only example. Other modules cited as being used for management purposes included 'Attendance' 45 percent, 'Midas' (Management Information Data Access System) 14 percent (though several schools noted they did not have this module yet) and 'Exams' (14\%) (though this module is only used in secondary schools). Several other modules 'STAR', 'Personnel', and 'Assessment' were also listed by several respondents. The elaboration given, of how their schools used these modules, could however have been interpreted as purely an administrative function.

\subsection{Discussion}

The survey only covered a small number of schools, and thus one can not read too much into the results. It would appear that the only major widespread educational management decision making processes that utilise IT are concerned with finances. However, it is 
apparent that many schools are still not using SIMS for management purposes informing decision making. The reasons for this may be:

- As Mitchell and Wild (1993) suggested, the system may not be flexible enough to provide information for management decisions;

- SIMS are in the process of re-writing all their modules to work under Microsoft ${ }^{\circledR}$ Windows ${ }^{\mathrm{rM}}$ and thus the constant updating of modules, and modules that do not integrate because some run under DOS and some under Windows, has slowed progress in this area;

- The training offered to senior managers is inappropriate. In evaluating the conference a significant number $(26 \%)$ offered the unsolicited opinion that the conference was far better than all the others they had attended on ITEM. The reason for this assertion was given as the conference was not a "'hands-on' press this key to do this course," which they felt was fine for clerical staff, but not for managers;

- The lack of management training of those who are not heads and some of the heads may well act as a block to using IT for management purposes.

\section{CONCLUSION}

Visscher's (1995) view concerning the developmental stages of CASA, does appear in the UK's case to need some slight modification to include a stage where IT is used widely for administration, but management usage is limited. Having examined the nature and use of MISs in section two of this paper it is apparent that there is a need for MISs in school to assist educational managers in planning, organising, controlling, reviewing, monitoring and evaluating the operation of their schools. However, for significant benefits to accrue, not only do educational MISs need to be well designed and implemented but educational managers must be aware, and take advantage of, the capabilities of their systems. It is also clear from the small survey that SIMS is not being used for management purposes, and some suggestions for this are made above. Developments that may lead to greater use of SIMS, in particular, and MISs in general, to support educational management are the production of new SIMS modules concerned with planning; increased competition from other suppliers; and the introduction of 'Headlamp'. 'Headlamp' (The Headteachers' Leadership and Management Programme) is a new national scheme in the UK to improve the quality of school management; unfortunately there is no mention of IT or MISs anywhere in the nationally specified course outline. (Teacher Training Agency, 1995).

\section{REFERENCES}

Bank, A. and Williams, C.R. (1987) The coming of instructional information systems, in Information Systems and School Improvement: Inventing the Future (eds. A. Bank and C.R. Williams), Teacher College Press, New York.

Cameron Fisher, J., Semrau, P. and Turban, E. (1990) Decision support systems in elementary and secondary educational administration. School Organisation, 10(1), 91-105.

Carter, D.S.G. and Burger, M. (1994) Curriculum management, instructional leadership and new information technology. School Organisation, 14(2), 153-168.

Coopers and Lybrand (1988) Local management of schools. A Report for the Department of Education and Science. DES, London. 
Davis, G.B. and Olson, M. H. (1985) Management information systems. McGraw-Hill, New York.

DES (1988) DES Circular No. 7/88. Education Reform Act: management of schools. DES, London.

Fidler, B. and Bowles, G. (Eds.) (1989) Effective local management of schools. Longmans in Association with British Educational Management and Administration Society, London.

Hicks, J.O. (1993) Management information systems: a user perspective (3rd ed.). West Publishing Company, St. Paul.

House of Commons (1988) Education Reform Act 1988: Chapter 40. HMSO, London.

Levacic, R. (1995) Local management of schools: analysis and practice. Open University Press, Buckingham.

Mitchell, S. and Wild, P. (1993) A task analysis of a computerised system to support administration in schools. Educational Administration and Management, 21(1), 53-61.

Selwood, I. (1995) The development of ITEM in England and Wales, in Information Technology in Educational Management. (eds. B.Z. Barta, M. Telem, and Y. Gev), Chapman \& Hall, London.

Strain, M. (1990) Resource management in schools: some conceptual and practical considerations, in Local Management of Schools: Some Practical Issues. (eds. E. Cave, and C. Wilkinson), Routledge, London.

Teacher Training Agency (1995) HEADLAMP - an initiative to support newly appointed headteachers. TTA, London.

Telem, M. (1990) DSS in educational organisations. Computers in Education, 14(1), 61-69.

Thierauf, J. R. (1987) Effective Management Information Systems (2nd ed.). Merrill, Ohio.

Visscher. A J. (1995) Computer assisted school administration and management: where are we and where should we go?, in Information Technology in Educational Management (eds. B.Z. Barta, M. Telem, and Y. Gev), Chapman \& Hall, London.

\section{BIOGRAPHIES}

Ian Selwood has been involved in IT in Education since the early seventies. Firstly as a teacher introducing computers into classrooms and teaching computer studies, then as an advisory teacher for computing and IT. In addition to writing textbooks for Computer Studies he has had papers published on a variety of topics concerned with IT in Education. Appointed as a lecturer in Information Technology in Education at the University of Birmingham in 1987, he is concerned with both the initial training of teachers and their further professional development. He has been involved in research and teaching about the use of IT in administration and management since 1988.

Helen Drenoyianni obtained her BEd at the University of Athens-Greece (1992) and she is currently a student at the University of Birmingham, registered for the degree of MEd with a sponsorship from the Greek State Scholarship Foundation. 